\title{
Refrigerated Storage Facilities - Aspects of Energy Efficiency, Design, Installation and Operation
}

\author{
Leelananda Rajapaksha
}

\begin{abstract}
The practice of refrigerated storage design and fabrication has been subjected to many subtle changes over the time due to concerns on energy and environment, improvements of thermal and fire properties of insulation material, advancements in fabrication technology, energy efficient space planning and issues of personal/property safety This paper highlights certain key aspects of planning and design of cold storages where changes with respect to properties/construction of insulation panels, refrigeration system selection, air tightness, in-use energy efficiency and environment considerations etc. have exerted considerable influences on the overall practice of cold room design installation and operation.
\end{abstract}

Keywords: Cold rooms, insulation panels, fire rated, refrigeration

\section{Introduction}

A refrigerated storage facility (commonly known as cold room) is an enclosed space in which the temperature and storage conditions are mechanically controlled. Food and agrarian industries depend very much on cold rooms to store products and raw materials. For example dairy products such as ice cream and yoghurt, processed meat, seed potato, and vegetable seeds such as 'kaoupi'. Depending on the product stored, the operating temperatures of cold rooms would be different.

The operating temperature of a cold room depends on many factors; thermal properties of the materials being stored and the expected storage durations are just two considerations. In general there are two basic types of storage facilities, those operated above $0^{\circ} \mathrm{C}$ (coolers) and those operated beiow $0^{\circ} \mathrm{C}$ (freezers). According to American Society of Heating, Refrigeration and Air conditioning Engineers (ASHRAE) a broader classification would be, i) controlled atmosphere for long-term storage of fruits and vegetables, ii) coolers at temperatures of $0^{\circ} \mathrm{C}$ and above, iii) freezers at -2 to $-3^{\circ} \mathrm{C}$ iv) low-temperature storage rooms for frozen products, usually maintained at -23 to $-29^{\circ} \mathrm{C}$, with a surplus of refrigeration for freezing products received [1]

Cold rooms use mechanical refrigeration systems to maintain controlled conditions inside, remove heat from the stored product and to offset any heat gains from the surroundings; through insulation panels, floor panels and doors etc. The refrigeration plant is usually a separate system linked with the cold room through a refrigerant circuit (direct system) or a secondary heat transfer fluid circuit such as glycol (indirect system). Figure 1 shows hardware arrangement of a direct system.

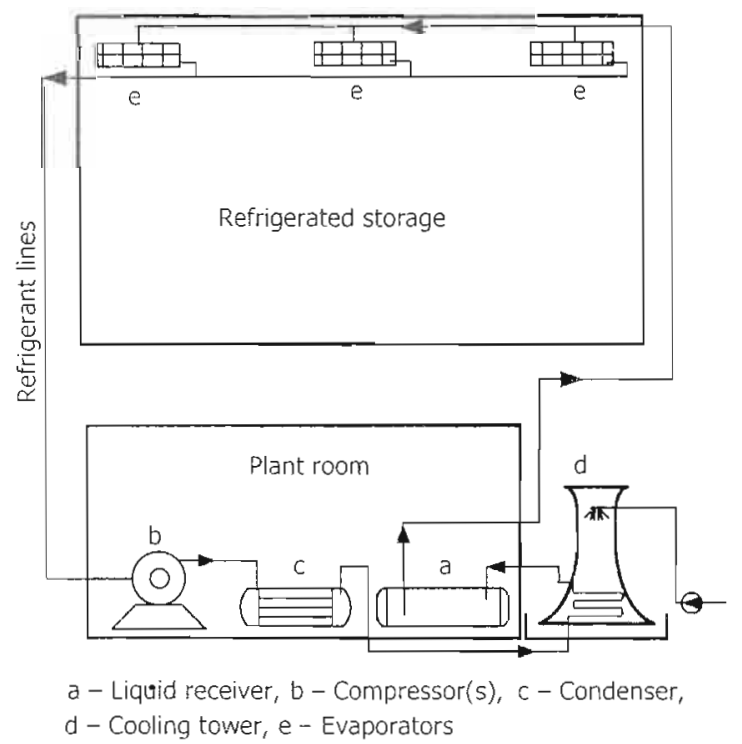

Figure 1-Basic hardware arrangement of a cold storage facility

Eng. (Prof.) Leelananda Rnapakshn, MIE(Sri Lanka), MIIAR, C. Eng., MIMechE, BScEng. (First Clnss Hons), MEng, PhD, Associnte Professor, Deparmonl of Mechnarical Engineering, Faculty of Engineering, University of Peraleniya. 
In the usual arrangement, the refrigerated storage is located inside a purpose-built building and the plant room in a separate section or a room depending on how the plant layout is planned.

The art of cold rooms fabrication has been subjected to many changes over the time with advancements of insulation material, panel construction and assembly technologies, increasing concerns on energy and environment, safety aspects (personal and property), and concerns about satisfying stringent insurance requirements (for protection against accidents including, fire). As a result, the focus of the construction of cold rooms has shifted towards making more air tight, better insulated facilities that are with relatively higher energy efficiency and could withstand fire at least for a specific period of time. This article presents a qualitative look at few selected aspects associated with design, fabrication and operation of cold storage facilities.

\section{Basic design considerations}

Fabrication of thermally insulated enclosure of a cold room and design of the refrigeration system involves many technical and operational considerations, some of which are interconnected. Among those some of the main considerations are i) rate of product coming in to the storage ii) resident time of the product, in case of foods this depend on the product texture and purpose of storage iii) allowable cooling rate that depends on nature of the product, thermal properties, moisture content and concerns about preserving flavour and freshness etc. iv) product leaving temperature after being stored v) effect of relative humidity on stored product vi) temperature distribution, a uniform distribution is desired in many cases vii) length of cold air plume and impingement on stored product viii) traffic and human movement in and out of storage area ix) effect of air circulation on both the product and the employees $x$ ) conditions of controlled environment (ventilation and total pressure if necessary), xi) product entering temperature, and xii) nature/thermal properties of packing material of the product.

\subsection{Location of site}

In selecting a location for a cold storage facility a number of conditions shall receive attention. These include access from main highway, space for movement of truck/long vehicles/lorries, room availability for future expansion, land cost, availability of power and water supply, waste and sanitary water disposal provisions, fire protection requirements of the local authority, noise of equipment, external appearance, tax and insurance requirements, plant security, undersoil bearing conditions and surface drainage etc

In general, cold room facilities are preferred to be located away from congested areas where the cost of increased transportation could be offset by better plant layout possibilities, while taking the advantage of lower-priced labour supply, or other economies of operation.

\subsection{Building size and configuration}

Building configuration and size considerations of a cold storage facility shall include the mode of transport in receiving/dispatching the goods, seasonal variation of product volumes and the possibility of multiple use of the facility, stacking arrangement, lot size of the product, the nature of the pellets and the product, movements of the product within the storage, requirements for personal and office facilities. However, in case of in-house storage, where product is manufactured and stored at a single location, the above may change depending on the requirements of the whole plant.

Most cold rooms are made with single-story structures. Small columns on wide centers permit palletized storage with minimal lost space. A modified one-story design is sometimes used to reduce horizontal traffic distances and land costs. An alternative is to locate non-productive services (including offices and the machinery room) on a secondfloor level, to permit full use of the ground level for production and storage.

Mechanization must be considered as well. In areas where land availability or cost is a concern, a high-rise refrigerated storage building may be a viable option. Designs that provide minimum overall costs restrict office facilities and utility areas to a minimum 


\subsection{Space planning and material handling}

A careful analysis of the intended application and skilful planning of cold room space could result in a more energy efficient and cost effective cold storage. In this regard the owner or the client should be pressed for all necessary data on the requirement of the storage.

ASHRAE recommend a typical height of at least 8.5 to $10.5 \mathrm{~m}$ space between the floor and structural steel to allow forklift operation. However, in Sri Lanka deviations form these are observed mainly due to unplanned expansions and cost consideration. The clear space above the pallet stacks is used for air units, air distribution, lighting, and sprinkler lines.

A 2 to $3 \mathrm{~m}$ minimum clear height is required from top of product to bottom of support structure to ensure there is no interference with drain pan and drain lines of air units. Greater clear heights are likely to be required if automated or mechanized equipment is used. Overhead space is relatively inexpensive, and the refrigeration requirement for the extra height is not significant in the overall plant cost. However, high stacking arrangements could have implications on insurance rates.

Planning for material handling within the storage is a very important aspect. This needs to consider all the design consideration and record keeping aspects as well to come up with an energy efficient and cost and time effective solution. Either to use mechanized transportation or to go for traditional pellet trucks depends on the analysis of all these consideration.

Products or material that needs be kept in a cold room are usually stacked preferably on racks. If the package itself is not suitable for stacking, pellets are usually used. A pellet is a platform of sufficient strength, usually made out of wood or plastic, on which the product is piled to regular shape such a cube, to facilitate movement of the load using a pellet truck for example. Different racking layouts, as shown in Figure 2, can be used depending on the dimension of the building and how the pellets are moved inside the storage.

The floor area in a facility where diverse merchandise is to be stored can be calculated on the basis of 130 to $160 \mathrm{~kg}$ per gross cubic metre

to allow about $40 \%$ for aisles and space above the pallet stacks [1]. In special-purpose or production facilities, products can be stacked with less aisle and open space, with an allowance factor of about $20 \%$ [1].

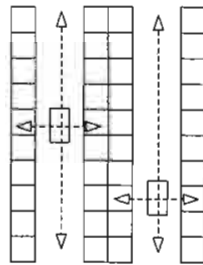

a) Single deep

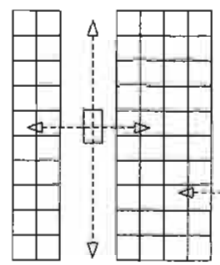

b) Double deep

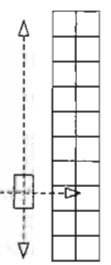

Figure 2 - Racking configurations when using a) pellet truck b) stacker crane [2]

\subsection{Structural strength and cost of insulation}

Cold storages are usually assembled inside purpose-build buildings; Figure 3 shows a typical arrangement. Usually certain refrigeration components such as receiver vessels, safety valves, controls and flow control valves, refrigerant pipes etc. are located above this top panel. As such certain amount of human traffic on the top panels is unavoidable, which makes the strength and stability of the roof panels (ceiling panels) important considerations. Therefore the top insulation panels are usually anchored to the roof structure by appropriate means, use of steel wires or rods of sufficient strength are common.

The optimum thickness of insulation is based on economic factors such as first cost of both the insulation and refrigeration equipment and energy and maintenance cost during the life of the facility. Figure 4 shows the present worth of the costs involved where the operating cost (mainly energy cost) is high at low insulation thicknesses, and the cost of insulation is high at large insulation thicknesses.

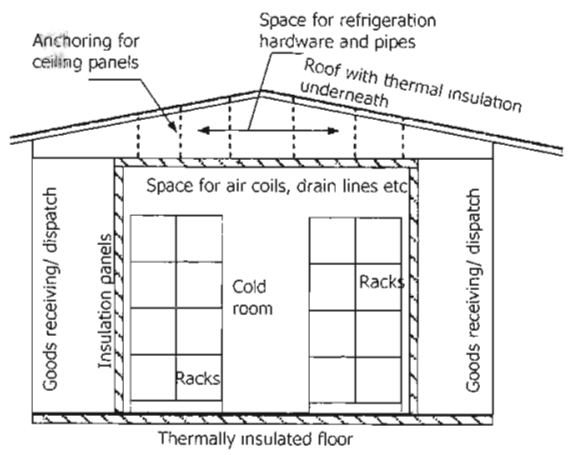

Figure 3 - Typical arrangement of a cold room (Sectional view) 
In certain cases, however, selection of thickness of roof insulation panels is driven by strength requirements than heat transfer consideration. Usually, for many available panels, the thickness selected based on strength on manufacturers' recommendations exceeds that based on heat transfer considerations. The same applies to the selection of wall insulation panels and insulation doors too.

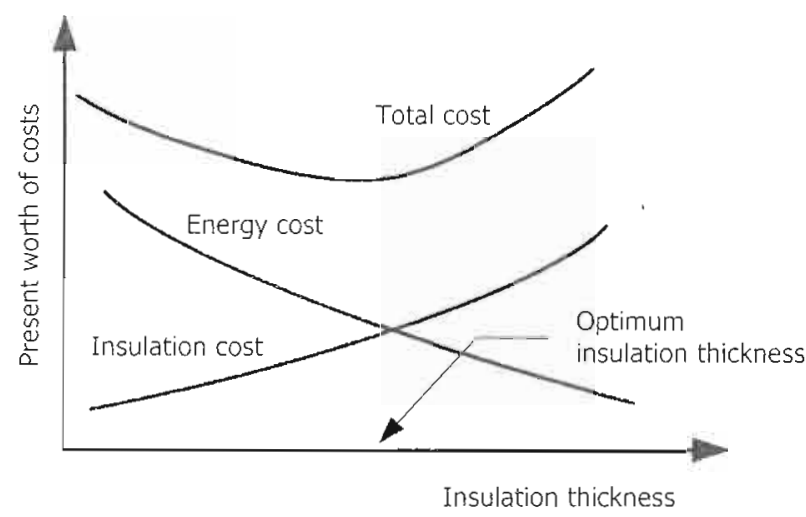

Figure 04 -Influence of insulation thickness on costs [2]

Goods receiving and dispatch areas facilitate convenient and orderly handing of materials. Considering the storage and outside temperatures, usually these areas are kept at an intermediate temperature. Such arrangement helps avoid the unnecessary and lengthy opening of cold room doors, which negatively reflects on energy consumption of the refrigeration plant.

\subsection{Air movement and air tightness}

Movement of conditioned air within a cold storage is planned at the design and space planning stages to help maintaining a uniform temperature distribution within the enclosure at the expense of least amount of energy. This requires consideration such as natural air movement due to density difference and the behaviour of forced air streams in the presence of obstacles, in this case the goods stored. Understanding of fluid dynamics and heat transfer is an essential element.

Usually, few inches of spaces are left between pellets (both ways, vertical and horizontal) to facilitate air movement through and across rows and columns of pellets. However, the airflow rate and velocity are important factors in reaching al] the pcllets stored and marinating the required temperature. In the selection of evaporator coils or cooling coils, due attention shall be paid in maintaining these two parameters, and perhaps suitably sized and placed additional fans/blowers could help achieve a better air circulation. In addition, the placement of the cooling coils within the cold room and the location of the temperature sensing devices/sensors are two important aspects that finally make sure a uniform temperature distribution and correct air flow pattern.

Air tightness of a cold storage is important in preventing moisture migration into the enclosure as well as maintaining overall energy efficiency of the storage. Whether the inside of the storage is heated or cooled, the air tightness directly relates to the rate at which conditioned air escape into the atmosphere (for example $\mathrm{m} 3 / \mathrm{h}$ at a defined pressure difference). Such undesirable loss of conditioned air represents additional load on the refrigeration system or heating system, which can be represented in terms of energy loss. For example the specified air tightness as of British building regulations is $10 \mathrm{~m}^{3} /$ h at $50 \mathrm{~Pa}$ for cold storage applications [3], however, careful planning and material selection could result in lover air leak levels.

The storage facility design and construction should be such that the energy efficiency of the building can be assessed. The design should consider the provisions for the conservation of fuel and power. The form and fabric performance of the building plays a vital role in the achievement of targeted in-use energy efficiency and reducing operation cost over the building's lifetime. Indirectly this helps achieve lower levels of $\mathrm{CO}_{2}$ emissions from the building and associated services.

In achieving optimum building energy efficiency factors such as insulation continuity, use of low air leakage material, and constant thermal properties of materials with respect to time are important.

\section{Insulation material}

Insulation is essential for low-temperature storage in order to reduce the refrigeration demand. The ideal insulation panel is light weight, structurally strong, with minimum thermal conductivity and 100\% resistance to moisture and other weather phenomena. A variety of insulation materials is available, with 
the options of prefabricated panels, or board form. In addition, certain insulation material come as foam applied directly to the surface to be insulated to obtain a monolithic insulation without joints.

\subsection{Panel construction}

Prefabricated board form insulations used in the fabrication of refrigerated storages are often called sandwiched panels. The panels are made of insulation layers of sufficient thickness and protected using metal sheets on either side, forming a sandwich. The metal sheet, which is also referred to as the cladding, is usually made of aluminum or steel and coated with some protective powder/paint. The cladding is corrugated to produce a groovy surface as shown in Figure 05 to deliver extra strength and to add an aesthetic character.

Most of the insulation materials used in making sandwiched panels are combustible. In order to improve the flammability thresholds and fire performances, fire inhibitors are added to the panel materials. The metal cladding (usually less than $1 \mathrm{~mm}$ thickness) also plays an important role in how the total insulation respond in the event of a fire. Depending on the fire properties of insulation material and the type of paint used on the surface, the cladding could enhances the fire resisting characteristics of the panel.

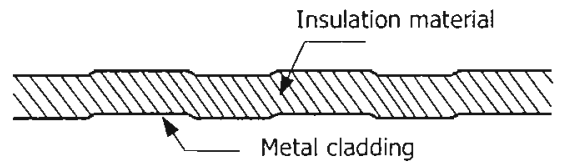

Figure 5 - Cross section of a sandwich panel

\subsection{Insulations and their properties}

Table 1 presents a summary of types of insulation materials generally available for cold storage applications.

The usual acronym used in the industry is given as this is the most convenient form of identification. Table 2 presents important characteristics and properties of common insulation materials.

Table 1 - Insulation panels types $[2,4]$

\begin{tabular}{|l|l|c|c|c|}
\hline Acronym & \multicolumn{1}{|c|}{ Material } & $\begin{array}{c}\text { Fire } \\
\text { rating }\end{array}$ & $\begin{array}{c}\text { Insulating } \\
\text { efficiency }\end{array}$ & Cost \\
\hline EPS & $\begin{array}{l}\text { Expanded } \\
\text { polystyrene }\end{array}$ & Poor & Fair & Low \\
\hline XPS & Extruded & Poor & Fair & Low \\
\hline
\end{tabular}

\begin{tabular}{|l|l|l|l|c|}
\hline & polystyrene & & & \\
\hline PUR & Polyurethane & Good & Good & Medium \\
\hline PIR & Polyisocyanurate & Good & Good & High \\
\hline MPHEN & $\begin{array}{l}\text { Modified } \\
\text { Phenolic }\end{array}$ & Good & Good & High \\
\hline
\end{tabular}

According to fire and heat transfer characteristics given in table 1 EPS and EPS based XPS both have poor fire resistance properties. Due to the thermoplastic nature of polystyrene the spread of fire is fairly intense with panels made of this material. PUR, on the other hand, has better fire and thermal characteristics as per Tables 1 and 2, so are PIR and MPHEN.

Table 2 - Properties of insulating material [4]

\begin{tabular}{|l|c|c|c|}
\hline \multicolumn{1}{|c|}{ Material } & $\begin{array}{c}\text { Density } \\
\left(\mathrm{kg} / \mathrm{m}^{3}\right)\end{array}$ & $\begin{array}{c}\mathrm{R} \text { value } \\
\left(\mathrm{m}^{2} \mathrm{~K} / \mathrm{W}\right)\end{array}$ & $\begin{array}{c}\text { Relative water } \\
\text { permeability }\end{array}$ \\
\hline $\begin{array}{l}\text { Extruded } \\
\text { polystyrene }\end{array}$ & 86 & 0.95 & medium \\
\hline Polyurethane & 32 & 1.14 & medium \\
\hline Polyisocyanurate & 32 & 1.16 & medium \\
\hline
\end{tabular}

Food processing and storage buildings often involve temperatures carrying potential fire risks. For example defrosting of cooling coils using electricity, radio frequency ovens, electrically heated drain lines etc. PIR is preferred in applications where comprehensive fire resistance property is needed as it has better fire resisting and retarding properties than PUR with better environmental performances (ozone depletion potential of PIR is zero).

In all three insulation materials, EPS, PUR and PIR, have certain permeability such that the thermal performances are affected by moisture. Therefore it is very important to maintain a good vapour barrier at every possible place where vapour could migrate into the panel, which increases the thermal conductivity, leading to increases in both the demand on refrigeration and energy consumption.

During the installation of services and refrigeration equipment, insulating panels have to be damaged to allow cable trays, refrigerant pipes etc. to pass through the panels. In all such cases, the damages should be treated properly and the insulation restored using standard methods, preferable using foam insulation injected to the damage area so that the possibility of vapour migrating into the exposed insulation is prevented (restore the vapour barrier). In the present context, use of environmentally friendly foam and blowing 
agent is encouraged and the foam has to have matching fire characteristics with the insulation panel.

\section{Refrigeration systems}

\subsection{Different systems}

Refrigeration system forms the heart of a cold storage facility. Field assembled industrial refrigeration plants and package refrigeration systems are the two main types used in cold storage applications.

As shown in Figure 1, in the first case (direct systems) components such as compressors, pressure vessels and intercoolers, condenser, cooling tower, refrigerant pumps etc., are located in the plant room and the evaporators in the cold room. Insulated refrigerant pipe network linking the plant room and cold room is a characteristic of this type of systems. These systems are mostly water cooled where a cooling tower or an evaporative condenser (less common in Sri Lanka) essential piece of hardware. A majority of direct systems have flooded evaporators, which makes the system performances less sensitive to the amount of refrigerant charge in the system or changes in the amount of charge within considerable limits.

On the contrary, a package system encompasses all the hardware of a vapour compression refrigeration system, including the evaporators on one platform; Figure 6, and come as a precharged unit ready to use.

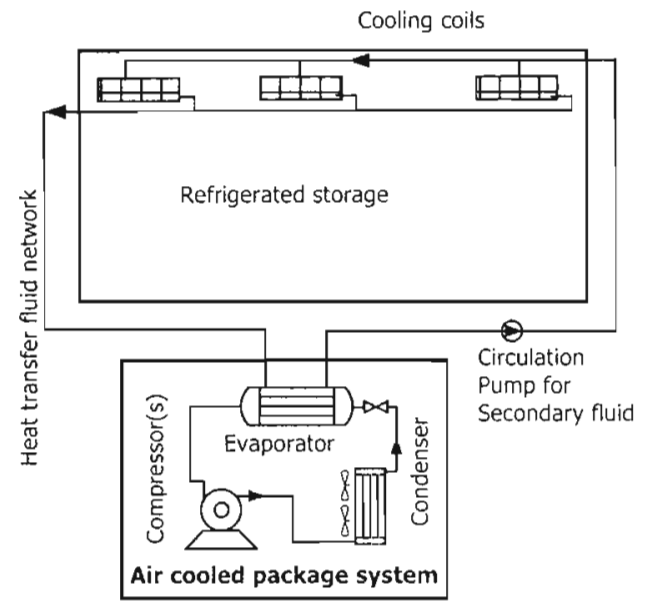

Figure 6 - Package based cooling system

The cold room is connected to the refrigeration system using a secondary heat transfer fluid pipe network (commonly referred to as glycol circuit). Separate coolers are located in the cold rooms in place of the evaporators of a direct system. A water cooled package will have a cooling tower in addition to the above hardware.

\subsection{Other considerations}

In addition to the design considerations given under section 2, there are certain specific issues that need the attention of refrigeration system designer in the context of pattern and purpose of use. In its regular operation of a cold room it is more likely that the cooling demand shows seasonal variations. In this respect, component sizing and selection of controls for the refrigeration system shall consider ways to obtain good part load efficiencies. Use of variable speed compressors is a very sensible approach in this regard.

Other factors that influence the capacity of cooling system are the type of defrosting used and meeting the cooling demand during defrosting, thermal properties of insulation panels selected, number of doors and the use pattern of the doors, nature of package material of the food material, packing density of the stored material.

Direct system uses latent heat of evaporation (involving phase change of the refrigerant from liquid to vapour) to provide necessary cooling to cold storage. In the case of a package system, the provision of cooling depends sensible heat transfer where the secondary fluid does not undergo a change of phase. This has implications on the size of coolers such that the coolers usually become much larger and bulkier than the evaporators of a direct system. Further, introduction of additional temperature difference between the refrigerant and secondary fluid results in relatively lower coefficient of performance of the refrigeration system.

\section{Operational issues}

\subsection{Door openings and opening duration}

Cold room door is the opening that separates outside environment from that of the inside, while allowing movements in and out of the cold storage. The temperatures and moisture content of the air on either side are different. 
Outside air tends to find its way in to the inside of the cold storage when cold room door is left open. Except for cold climates, the outside air is warm and carries a considerable amount of moisture (high relative humidity).

Outside air entering a cold storage reflects negatively on the refrigeration system as this air represent additional latent and sensible heat loads, which could be proportional to the opening duration of door. This infiltration cooling load is rather substantial in magnitude and could be up to $25 \%-30 \%$ of the total refrigeration load [5]. Sensible part is due to temperature of air, which is higher than that in the cold room, and latent part is due to the moisture in outside air that finally will end up on the cuoling coil surface as frost. This situation results in relatively longer defrosting durations, which may not be desirable depending on the refrigeration system capacity, required air movement pattern in the cold room and with respect to maintaining homogeneous product temperature.

In large cold rooms where a number of doors are available and door openings are frequent, the additional energy consumption due to the heat load associated with outside air migration can be substantial and represent a considerabie energy bill. On energy saving perspective, a scheduled upening pattern of the doors are preferred where in each opening the duration is kept to a minimum by careful study of the use pattern. Further, installation of strip curtain or air curtain at entrances help reduce additional infiltration load coming into the cold room through opened doors.

\subsection{Defrosting and removal of moisture}

Defrosting too represent a considerable refrigeration load, however, relatively smaller than infiltration load due to door openings [2]. During defrosting the ice formed on cooling coils are melted and the resulting water is left to be collected into the defrost pan of the coil. Depending on the temperature inside the cold storage, this water could freeze again in the pan or in the drain lines that drain the collected defrost water out of the cold room. It is important to remove this water to reduce the chances of fungi and bacterial growth inside the cold room.

To complete the defrosting process satisfactorily, the defrost pan and the drain lines are heated. Defrost pan could be heated using hot refrigerant vapour or using electrical heaters. The drain lines are usually electrically heated where heating element is wrapped around the drain line. Due to this arrangement, proper control of drain line heaters/heating process is very important with respect to potential fire risk.

\section{Conclusions}

The article attempted to highlight areas which a designer of cold storage shall take into account in the approach of cold room design. The importance of consumption were highlighted. How the practice of cold room usage could affect the overall energy consumption and satisfactory performance of the refrigeration plant were also highlighted as the would be useful for a young practicing engineer.

\section{References}

1. ASHRAE Handbook, HVAC Applications, 2003.

2. W F Stoecker, 1995, Industrial Refrigeration Volume II, BNP Publications, Michigan.

3. The building regulations 2000, Conservation of fuel and power - L2A, (2006), Published by NBS, part of RIBA enterprises Ltd, UK.

4. Coldroom panels, polyurethane foam and fire ratings: an update, 2004, Foster refrigeration blue paper, UK (www.fosterrefrigerator.co.uk), visited $14^{\mathrm{th}}$ June 2008.

5. W F Stoecker, 1987, Industrial Refrigeration Volume I, Business News Publication company. 